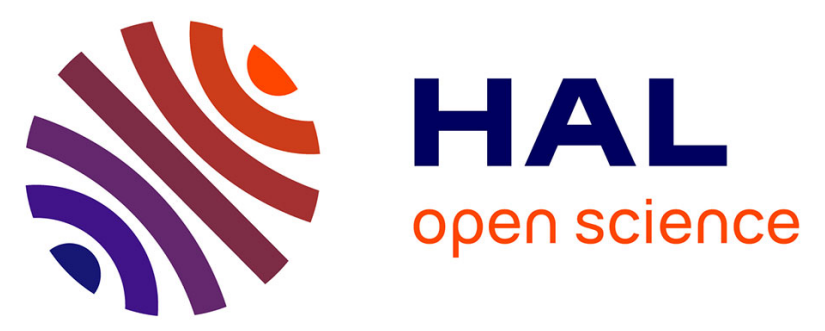

\title{
Multiscale physicochemical characterization of a short glass fiber-reinforced polyphenylene sulfide composite under aging and its thermo-oxidative mechanism
}

Zuo Peiyuan, Abbas Tcharkhtchi, Mohammadali Shirinbayan, Joseph Fitoussi, Farid Bakir

\section{To cite this version:}

Zuo Peiyuan, Abbas Tcharkhtchi, Mohammadali Shirinbayan, Joseph Fitoussi, Farid Bakir. Multiscale physicochemical characterization of a short glass fiber-reinforced polyphenylene sulfide composite under aging and its thermo-oxidative mechanism. Polymers for Advanced Technologies, 2019, 30, pp.584-597. 10.1002/pat.4495 . hal-02063535

\section{HAL Id: hal-02063535 \\ https://hal.science/hal-02063535}

Submitted on 11 Mar 2019

HAL is a multi-disciplinary open access archive for the deposit and dissemination of scientific research documents, whether they are published or not. The documents may come from teaching and research institutions in France or abroad, or from public or private research centers.
L'archive ouverte pluridisciplinaire HAL, est destinée au dépôt et à la diffusion de documents scientifiques de niveau recherche, publiés ou non, émanant des établissements d'enseignement et de recherche français ou étrangers, des laboratoires publics ou privés. 


\title{
Multiscale physicochemical characterization of a short glass fiber-reinforced polyphenylene sulfide composite under aging and its thermo-oxidative mechanism
}

\author{
Peiyuan Zuo ${ }^{1}$ (D) | Abbas Tcharkhtchi ${ }^{1}$ | Mohammadali Shirinbayan ${ }^{1}$ | Joseph Fitoussi ${ }^{1}$ | \\ Farid Bakir ${ }^{2}$
}

${ }^{1}$ PIMM-UMR CNRS 8006, Arts et Métiers ParisTech, 75013 Paris, France

${ }^{2}$ Dynfluid, Arts et Métiers ParisTech, 75013 Paris, France

Correspondence

Peiyuan Zuo, Arts et Métiers ParisTech, PIMM-UMR CNRS 8006, 151 Boulevard de l'Hôpital, 75013 Paris, France.

Email: 2015-1027@ensam.eu
In this paper, the thermo-oxidation for a short glass fiber-reinforced polyphenylene sulfide (PPS/GF) composite was experimentally and theoretically studied by a wide range of physicochemical and mechanical techniques. The accelerated thermal aging temperatures were fixed at $100^{\circ} \mathrm{C}, 140^{\circ} \mathrm{C}, 160^{\circ} \mathrm{C}, 180^{\circ} \mathrm{C}$, and $200^{\circ} \mathrm{C}$. Firstly, the results of weight loss under aging indicate the formation of volatile products because of chain scission of end groups. Also, Fourier-transform infrared spectroscopy (FTIR) results suggest that the formation and accumulation of carbonyl group arising from the formation of hydroperoxides in oxidative propagation process. In all cases of different thermal oxidation temperatures, it is hard to observe some significant change about the concentration of carbonyl group during the induction time. This induction time depends inversely on the oxidation temperature. Moreover, the cross-linking and chain scissions exist together according to the results of rheological results and it is easier to see the cross-linking phenomenon at the beginning of oxidation while the chain scissions are more pronounced, with the oxidation process developing further. In aspect of mechanical properties, $\sigma_{\max }$ increases at the beginning of oxidation because of cross-linking, and subsequently, the $\sigma_{\max }$ always decreases because of thermo-oxidation of the PPS matrix. In addition, the detailed thermo-oxidation processes are fully discussed in the end of this study. A mechanistic schema has been proposed to present different oxidation reactions of PPS polymer and then a kinetic model has been extracted from this mechanism. Afterwards, the model has been verified by experimental results at different temperatures.

\section{KEYWORDS}

aging, mechanical properties, polyphenylene sulfide (PPS), rheology, thermo-oxidation mechanism modeling

\section{1 | INTRODUCTION}

Polyphenylene sulfide (PPS) is a thermoplastic polymer consisting of aromatic rings linked by sulfur atoms. It is widely used as a high performance engineering plastic with a unique combination of excellent mechanical and thermal properties. In detail, it is applied in a wide range, including automobile pieces, precision instruments, and aerospace products. $^{1-4}$
As an engineering composite, PPS composite possesses hightemperature resistance combined with good mechanical properties. In our previous research, ${ }^{5}$ we have comprehensively characterized this PPS composite and also fully discussed their fatigue behaviors. Moreover, since thermal treatment can have an important effect on mechanical properties of PPS materials, there are various researches focusing on this aspect. For example, Ma et al ${ }^{6}$ studied the mechanical behaviors of PPS materials after heat treatment and they found 
excessive heat treatment, longer than 2 days, resulted in over oxidative cross-linking and was detrimental to the thermal mechanical properties of the samples at high temperature. Zhai et $\mathrm{al}^{7}$ also found the mechanical properties of glass fiber-reinforced PPS (PPS/GF) composites were negatively affected by thermal treatment. Moreover, in some study, ${ }^{8}$ the authors verified the effect of thermal treatment on the tensile and in-plane shear behavior of carbon fiber-reinforced PPS composite specimens and the results suggested that there was a significant degradation of mechanical properties, and this degradation can be enhanced by increasing treatment temperature and time.

On the other hand, exploring the thermal degradation details about PPS materials can give us some more useful guidance in practice. Many researchers had focused their attention on aspect of thermal degradation of sulfur-containing aromatic polymers, PPS polymers, and their reinforced composites. For example, Yamashita et $\mathrm{al}^{9}$ studied the photodegradation of sulfur-containing aromatic polymers: polyethersulfone (PESF) and polysulfone (PSF). It was found that the main chain scission and cross-linking occurred simultaneously during the photodegradation process of these two polymers. Moreover, Ehlers et $\mathrm{al}^{10}$ clarified in-depth about the cross-linking phenomenon during the PPS aging process. They concluded that cleavage of carbon-sulfur bonds and abstraction of hydrogen from some of the rings resulted in chain fragments with phenyl- and phenylmercapto end groups. Also, cleavage of the $\mathrm{C}-\mathrm{SH}$ bonds and abstraction of more hydrogen favored to produce hydrogen sulfide. Moreover, Li et al ${ }^{11}$ studied thermal degradation process of PPS films in different atmospheres with the temperature ranging from $25^{\circ} \mathrm{C}$ to $790^{\circ} \mathrm{C}$. In that research, they pointed out that most polymers contained weak bonds that were expected to break with a higher probability than other stronger bonds. When the thermal energy began to surpass the bond energies of various bonds in the PPS chains, a random chain scission took place and the rate of degradation would be enhanced rapidly. Also, Black et al ${ }^{12}$ concluded the degradation mechanism of PPS involved a combination of cross-linking and chain scission reactions. In addition, some researchers ${ }^{13}$ also studied the different aspects of PPS degradation and stabilization. They found that chemical end groups of polymer played an important role in the thermal oxidation of PPS and the coloration reasons of PPS were mainly derived from the accumulation of specific, colored products (eg, phenyl-phenyl moieties) and some intermolecular products. In other aspect, there are also some reports using different ways to investigate the degradation of PPS. For example, Perng et $\mathrm{al}^{14}$ researched thermal decomposition characteristics of PPS by stepwise pyrolysis/gas chromatography/mass spectrometry (Py-GC/MS) and thermogravimetric analysis/mass spectrometry (TG/MS) techniques, they clarified the mechanism and kinetic model for thermal decomposition of PPS in-depth. Similarly, Christopher et $\mathrm{al}^{15}$ studied thermal degradation of Poly (phenylene sulfide) by following the weight loss during the time of aging. All of these applied techniques are very powerful and favorable to explore extensive thermal oxidation mechanism of PPS materials.

However, there is no report talking about the exact thermooxidation process of PPS under air or oxygen and there is no research details concerning quantitative calculation of oxidation products from PPS materials during accelerated thermal aging process. Especially, there is no study talking about modeling of thermo-oxidation of PPS, but this modeling is very important to predict the lifetime of PPS materials.

So, in this paper, the main work is to follow the evolution of physicochemical and mechanical properties of PPS during accelerated aging at different temperatures. Afterwards, a mechanism has been proposed to describe the thermo-oxidation process of PPS materials. This mechanism can give us an access to obtain a kinetic model and also it can not only remarkably contribute to quantitative calculation of thermal oxidation products, but also leads to efficient prediction of thermos-oxidative lifetime for PPS materials.

\section{I MATERIALS AND CHARACTERIZATION METHODS}

\subsection{Materials and sample preparation}

PPS composite materials reinforced with short glass fibers $30 \%$ weight fraction) were kindly supplied by Valeo Company in France. According to our previous research results, ${ }^{5}$ image analysis of optical microscopy (OM) reveals short glass fibers with a diameter of about $15 \mu \mathrm{m}$ and the length from 70 to $360 \mu \mathrm{m}$ with an average length of about $200 \mu \mathrm{m}$ after pyrolysis.

Moreover, the original plate with a thickness of $3 \mathrm{~mm}$ was used for preparing the films. First of all, one part of an original plate was cut and pasted on a base support. Then this complete specimen with a base support was fixed on a LEICA microtome. The LEICA RM2255 is a fully automatic, motorized rotary microtome with a separate control panel for creating thin sections of specimens of varying hardness for various domains, including industry, medicine and biology, etc. The apparatus can set up different moving forward speeds and obtain the variously needed cutting thickness by controlling accurate location distance automatically. For this study, the thickness of film is $20 \mu \mathrm{m}$ and every film is put into one separate bag to stock and use in thermal aging research. Also, other basic parameters can be referred in Table 1.

Also, it should be emphasized that two kinds of specimen were used in this study. One kind is a film with a thickness of $20 \mu \mathrm{m}$, which was obtained by microtome. The other samples have a standard dimension (see Figure 1). In fact, the received PPS plates were cut by the Lokicoup Company with the desired sample dimension we have designed. All samples for the mechanical tests have the same standard dimensions.

The films with a thickness of $20 \mu \mathrm{m}$ (obtained from PPS plate) and dog-bone shape samples were put into the ovens and the aging temperatures were fixed at $100^{\circ} \mathrm{C}, 140^{\circ} \mathrm{C}, 160^{\circ} \mathrm{C}, 180^{\circ} \mathrm{C}$, and $200^{\circ} \mathrm{C}$. It is necessary to describe that the accurate thermal test conditions are as follows:

1. For weight change test, four aging temperatures $\left(100^{\circ} \mathrm{C}, 140^{\circ} \mathrm{C}\right.$, $180^{\circ} \mathrm{C}$, and $200^{\circ} \mathrm{C}$ ) were recorded from 0 hours to a maximum of 5256 hours.

2. For the Fourier-transform infrared spectroscopy (FTIR) test, the samples were taken at the aging time ranging from 0 hours to a 
TABLE 1 Basic parameters of polyphenylene sulfide (PPS) composite materials

\begin{tabular}{llllll} 
PPS & Fiber type & Density $\left(\mathrm{g} / \mathrm{cm}^{3}\right)$ & $\mathrm{T}_{\mathrm{g}}\left({ }^{\circ} \mathrm{C}\right)$ & $\mathrm{T}_{\mathrm{m}}\left({ }^{\circ} \mathrm{C}\right)$ & $\mathrm{T}_{\mathrm{c}}\left({ }^{\circ} \mathrm{C}\right)$ \\
Parameters & Short glass fiber & 1.58 & 109 & 283 & 241 \\
\hline
\end{tabular}

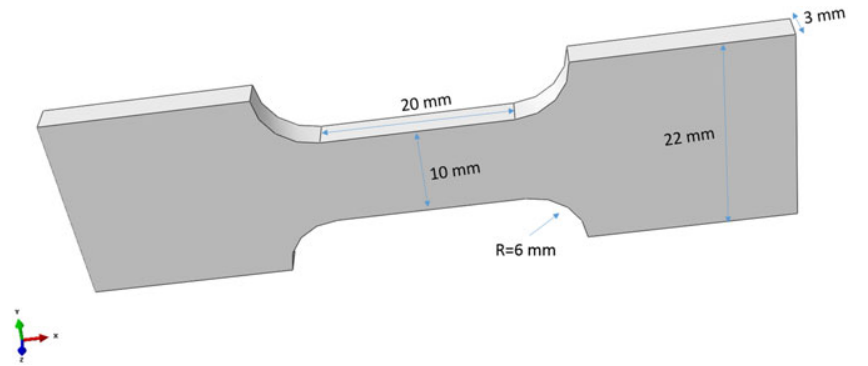

FIGURE 1 The detailed dimension of glass fiber-reinforced polyphenylene sulfide (PPS/GF) sample for tensile tests [Colour figure can be viewed at wileyonlinelibrary.com]

maximum of 5256 hour at four aging temperatures $\left(140^{\circ} \mathrm{C}\right.$, $160^{\circ} \mathrm{C}, 180^{\circ} \mathrm{C}$, and $200^{\circ} \mathrm{C}$ ).

3. For the dynamic mechanical analysis (DMTA) test, four aging temperatures $\left(100^{\circ} \mathrm{C}, 140^{\circ} \mathrm{C}, 180^{\circ} \mathrm{C}\right.$, and $\left.200^{\circ} \mathrm{C}\right)$ were recorded from 0 hours to a maximum of 5688 hours.

4. For the ultraviolet (UV) test, a virgin film sample was used.

5. For rheological tests, virgin samples and aged samples at $180^{\circ} \mathrm{C}$ and $200^{\circ} \mathrm{C}$ were used. The aging time was chosen from 0 hours to a maximum of 606 hours.

6. For $\mathrm{OM}$ analysis, virgin sample and aged samples at $180^{\circ} \mathrm{C}$ and $200^{\circ} \mathrm{C}$ were used. The aging time was chosen from 0 hours to a maximum of 5256 hours.

7. For tensile test, four aging temperatures $\left(100^{\circ} \mathrm{C}, 140^{\circ} \mathrm{C}, 180^{\circ} \mathrm{C}\right.$, and $200^{\circ} \mathrm{C}$ ) were chosen, and the aging time was from 0 hours to a maximum of 5256 hours.

\section{2 | Characterization methods}

\subsection{1 | Weight loss characterization}

The dog-bone-shaped samples (in Figure 1) were prepared before the test, and afterwards, the samples were suspended in ovens, which can keep them in full contact with air at different temperatures. The weight of the sample was measured in different interval time points to observe the residual weight percent $\mathrm{W} \%$, and the calculation equation is as follows:

$$
W \%=\frac{W_{t}}{W_{0}} * 100 \%
$$

Where $W_{t}$, is the weight in the time of $t$ and $W_{0}$ is the weight of virgin sample.

\subsection{2 | Tensile tests}

Tensile properties were measured with an INSTRON 5966 machine at room temperature. The test velocity was $0.5 \mathrm{~mm} / \mathrm{min}$. Dog-boneshaped samples (see Figure 1) were employed. The received PPS plates were cut by the Lokicoup Company with the desired sample dimension we needed. All samples for the mechanical tests have the same standard dimensions.

\subsection{3 | Infrared analysis (FTIR)}

FTIR spectrometry was used to characterize the extent of polymer oxidation, using a Nicolet impact 410 spectrophotometer in transmission mode. Measurements were made on spectra resulting from the accumulation of 32 runs, the resolution being $4 \mathrm{~cm}^{-1}$. The film with a thickness of $20 \mu \mathrm{m}$ (preparation by microtome) was used. The absorbance of carbonyl was converted to the concentration using a molar absorptivity of $300 \mathrm{~L} \mathrm{~mol}^{-1} \mathrm{~cm}^{-1}$ at the peak maximum $\left(1780 \mathrm{~cm}^{-1}\right) .{ }^{16}$ Also the concentration of $[\mathrm{C}=\mathrm{O}]$ or other degradation products can be calculated according to the Beer-Lambert law, which is as follows:

$$
C=\frac{A}{\varepsilon \cdot \mathrm{e}}
$$

Where $A$ is the absorbance or optical density for the FTIR spectrum, $e$ is the thickness of samples $(20 \mu \mathrm{m})$ and $\varepsilon$ is the extinction coefficient. Similarly, the concentration of $[\mathrm{C}-\mathrm{S}]$ and $[\mathrm{C}-\mathrm{H}]$ are calculated using the same way and the extinction coefficients for $[\mathrm{C}-\mathrm{S}]^{17}$ and $[\mathrm{C}-\mathrm{H}]^{18}$ are 114 and $42 \mathrm{~L} \mathrm{~mol}^{-1} \mathrm{~cm}^{-1}$, respectively.

It should be emphasized that different film thickness will change the final values of concentration. In this manuscript, a standard thickness of $20 \mu \mathrm{m}$ was chosen for all samples under study.

\subsection{4 | Rheological characterization}

Viscosity measurements were conducted by the Rheometer MCR 502 from Anton Paar. The tests were performed on film samples at different temperatures under nitrogen, as well as in a plate-plate configuration with a gap of $1 \mathrm{~mm}$.

There are three main rheological tests in this study:

1. To see the viscosity evolution as a function of aging condition at $180^{\circ} \mathrm{C}$, virgin and aged specimens were used and the experimental temperature was fixed at $290^{\circ} \mathrm{C}$ (strain $=0.2 \%$, angular frequency $=1 \mathrm{rad} \mathrm{s}^{-1}$ ).

2. To see the viscosity evolution as a function a time at a fixed temperature, one virgin specimen was used and the isothermal temperature was fixed at $290^{\circ} \mathrm{C}$ (strain $=0.2 \%$, angular frequency $=1 \mathrm{rad} \mathrm{s}^{-1}$ ). 
3. To compare different rheological properties, virgin and aged samples from $180^{\circ} \mathrm{C}$ and $200^{\circ} \mathrm{C}$ were used and the experimental temperature was fixed at $300^{\circ} \mathrm{C}$ (strain $=0.2 \%$, angular frequency ranging from 0.1 to $100 \mathrm{rad} \mathrm{s}^{-1}$ ).

\subsection{5 | Optical microscopy analysis (OM)}

The oxidation layer thickness for PPS sample is measured by the OM technique and the plate samples are observed via Zeiss Axio Imager 2. The detailed operation can be briefly described as follows: virgin or aged samples from ovens were cut from crossing section and the prepared samples with a crossing section surface were observed by OM apparatus. The objective lens was chosen $\times 5$ and the corresponding scale label was put on lower right corner of images. Finally, every three thickness points were measured to obtain the average thickness of oxidation layer.

\subsection{6 | Dynamical mechanical analysis (DMTA)}

DMTA tests have been performed on PPS/GF samples using DMTA Q800 instrument in order to measure the main transition temperatures and the characterization of viscoelastic behavior. The tests have been realized under the following condition: alternating bending configuration was necessary and test temperatures were chosen from $25^{\circ} \mathrm{C}$ to $200^{\circ} \mathrm{C}$ with a frequency ranging from 0.1 to $50 \mathrm{~Hz}$ as well as temperature rate at $0.5^{\circ} \mathrm{C} \mathrm{min}^{-1}$. The sample had a rectangular shape with a dimension of $35 \times 12 \times 3 \mathrm{~mm}^{3}$.

\subsection{7 | Ultraviolet (UV) spectrometry analysis}

The UV spectrometry analysis does not only check the absence or presence of stabilizers in the materials, but can also be used to quantitatively calculate the amount of absent or present products. This spectra under study is obtained using PERKINELMER UV-visible spectrophotometer (model Lambda 5), equipped with an integrated sphere. They are recorded in absorbance mode 66 over a spectral range extending from 200 to $400 \mathrm{~nm}$. The analysis of the data is done by applying the same method of IR spectrometry using the BeerLambert law.

\section{3 | RESULTS}

\section{1 | Weight loss characterization}

Thermo-gravimetric method is commonly used to follow the oxidation process, but it is important to emphasize that this method can only give information about the weight loss related to the volatile oxidation products, which means the small molecules are formed due to the scission at the end of molecular chains. Also, it should be noted that this technique cannot give more information when the chain scission is not at the end of chain and when the oxidative products are not volatile.
Figure 2 records the residual weight percent of PPS/GF samples as a function of aging time in the ovens fixed at different temperatures $\left(100^{\circ} \mathrm{C}, 140^{\circ} \mathrm{C}, 180^{\circ} \mathrm{C}\right.$, and $200^{\circ} \mathrm{C}$, respectively). For all of these tests, the weight loss ratio remains small (below 1\%) until approximately 5000 hours, while the degradation trend is different under different oxidation temperatures. The result suggests that the weight loss contains several steps and also depends on oxidation temperatures. At the beginning, the samples loss some weight because of the evaporation of humidity or moisture in matrix. After long time aging (more than $2000 \mathrm{~h}$ ), the sample aged under $100^{\circ} \mathrm{C}, 140^{\circ} \mathrm{C}$ stay stable without obvious weight loss while the weights of samples under $180^{\circ} \mathrm{C}$ and $200^{\circ} \mathrm{C}$ decrease obviously. This indicates that weight loss is highly dependent on applied thermal aging temperature.

\subsection{Evolution of chemical groups in PPS/GF composite}

Figure 3 records the FTIR spectrum comparison of PPS from virgin sample and aged sample at $200^{\circ} \mathrm{C}-504$ hours. Several remarkable changes can be noticed from the spectrum. First of all, the densities of $\mathrm{C}-\mathrm{H}$ bonds corresponding to the wavenumber position of 2856 and $2923 \mathrm{~cm}^{-1}$ decrease sharply during aging process at $200^{\circ} \mathrm{C}$. Also, it should be emphasized that after 504 hours, the $\mathrm{C}-\mathrm{H}$ bond can hardly be detected, which suggests that a large amount of $\mathrm{C}-\mathrm{H}$ bonds break during aging. Moreover, one can observe that $\mathrm{C}=\mathrm{O}$ chemical groups increase in some relative extent after 504 hours. For $\mathrm{C}-\mathrm{S}$ chemical bonds, it is difficult to distinguish some change from this whole spectrum. So, to get more information of the FTIR spectrum, more details about different chemical group concentrations are calculated from enlarged wavenumber positions corresponding to different chemical groups, which are shown in the following text.

In detail, the evolution of [C-S] concentration is shown in Figure 4. It is interesting to notice that the $[\mathrm{C}-\mathrm{S}]$ concentration has a sudden decrease at the beginning of aging and subsequently it stays stable for a long time. But it should be emphasized that after

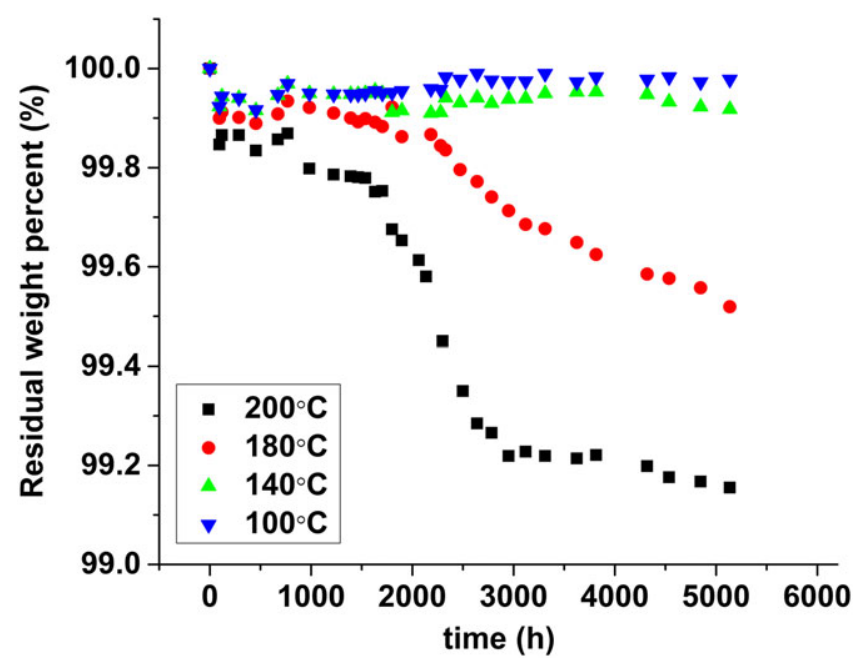

FIGURE 2 Residual weight percent versus different thermal aging temperatures and aging time [Colour figure can be viewed at wileyonlinelibrary.com] 


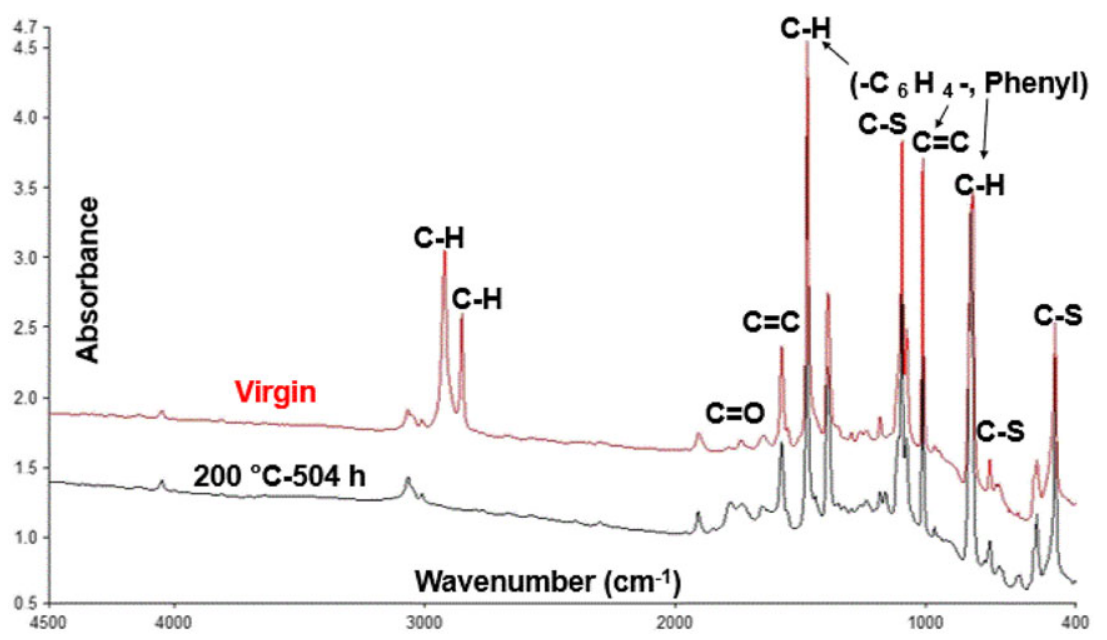

FIGURE 3 Fourier-transform infrared spectroscopy (FTIR) results for different polyphenylene sulfide (PPS) samples (virgin sample and aged sample at $200^{\circ} \mathrm{C}-504 \mathrm{~h}$ ) [Colour figure can be viewed at wileyonlinelibrary.com]

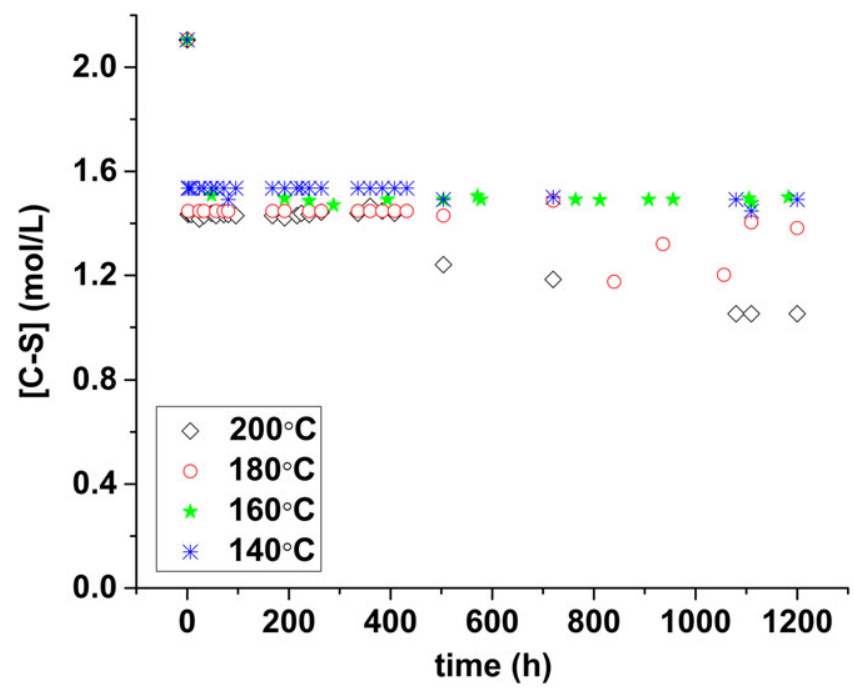

FIGURE $4 \mathrm{C}-\mathrm{S}$ concentration $\left(1075 \mathrm{~cm}^{-1}\right)$ evolution as a function of oxidation time under different temperatures [Colour figure can be viewed at wileyonlinelibrary.com]

500 hours, the $[\mathrm{C}-\mathrm{S}]$ concentration starts to decrease in higher thermal oxidation temperatures $\left(\mathrm{eg}, 180^{\circ} \mathrm{C}, 200^{\circ} \mathrm{C}\right)$. How can we explain this phenomenon? The answer is as follows: according to the literature, ${ }^{19,20} \mathrm{C}-\mathrm{S}\left(276 \mathrm{~kJ} \mathrm{~mol}^{-1}\right)$ is weaker than $\mathrm{C}-\mathrm{H}\left(414 \mathrm{~kJ} \mathrm{~mol}^{-1}\right)$ bond and $\mathrm{C}=\mathrm{C}\left(477 \mathrm{~kJ} \mathrm{~mol}^{-1}\right)$ from the view of bond energy theory. It suggests obviously that the $[\mathrm{C}-\mathrm{S}]$ concentration slightly decreases because the weakest bond energy of $\mathrm{C}-\mathrm{S}$ bond leads to breakage in the position of $\mathrm{C}-\mathrm{S}$ bond. However, it should also be emphasized that PPS is one kind of polymer with sulfur atoms, which can easily have numerous cross-linking reactions, in return, leading to formation of other more stable cross-linking products containing $\mathrm{C}-\mathrm{S}$ bonds.

The evolution of $[\mathrm{C}-\mathrm{H}]$ concentration is shown in Figure 5 , which is calculated according to the results of wavenumber position of $2923 \mathrm{~cm}^{-1.21}$ It is obvious to see that $[\mathrm{C}-\mathrm{H}]$ concentration evolution highly depends on oxidation temperatures. In general, higher temperature corresponds to shorter induction time. For example, it can be seen that at $200^{\circ} \mathrm{C}$, the $[\mathrm{C}-\mathrm{H}]$ concentration decreases sharply starting from 33 hours while induction time at $180^{\circ} \mathrm{C}$ is about

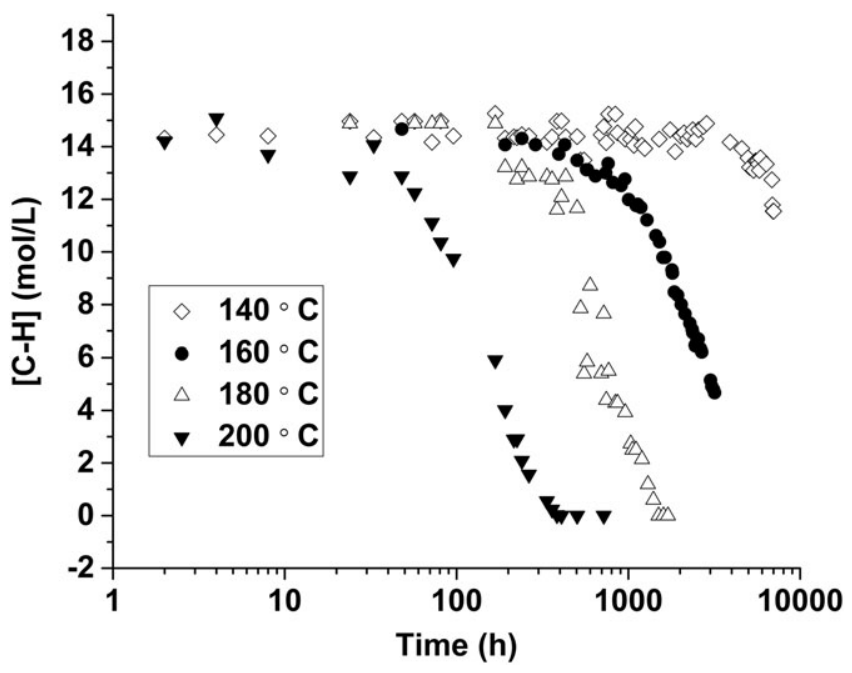

FIGURE $5 \mathrm{C}-\mathrm{H}$ concentration $\left(2923 \mathrm{~cm}^{-1}\right)$ evolution versus oxidation time under different temperatures

192 hours. This indicates that decreasing oxidation temperature leads to significant delay of induction time. Comparatively, the propagation process tends to be finished after 400 hours at $200^{\circ} \mathrm{C}$, while this time point for $180^{\circ} \mathrm{C}$ is by 2000 hours. Besides, at $160^{\circ} \mathrm{C}$, the induction time and termination time of $\mathrm{C}-\mathrm{H}$ bond rupture tend to be longer than the case in $180^{\circ} \mathrm{C}$ and $200^{\circ} \mathrm{C}$. On the contrary, at $140^{\circ} \mathrm{C}$, the corresponding oxidation phenomenon is too weak to detect until 5000 hours exposition according to the concentration of $[\mathrm{C}-\mathrm{H}]$. Until this time point of 5000 hours, $[\mathrm{C}-\mathrm{H}]$ concentration does not appear an obvious decreasing trend.

Figure 6 shows the experimental results of $\mathrm{C}=\mathrm{O}\left(1780 \mathrm{~cm}^{-1}\right)$ concentration evolution versus oxidation temperature and time. ${ }^{21}$ In all cases, the curves have three different periods: In the first period, there is no change of $\mathrm{C}=\mathrm{O}$ concentration and it remains nearly constant. It is interesting to note that at $200^{\circ} \mathrm{C}$, the induction time of oxidation is less than 30 hours, while this value at $180^{\circ} \mathrm{C}$ is about 300 hours. In addition, it is noteworthy that the oxidation phenomenon at $160^{\circ} \mathrm{C}$ has a moderate oxidation trend before 1000 hours of oxidation. Comparatively, in the case of oxidation temperature at $140^{\circ} \mathrm{C}$, there is no obvious increase of $[\mathrm{C}=\mathrm{O}]$ until 1200 hours. 


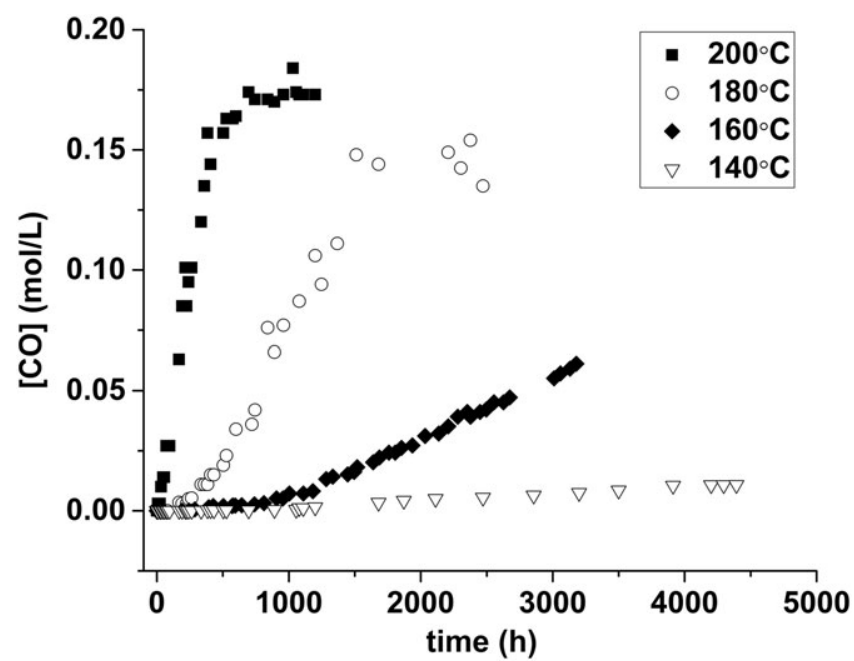

FIGURE $6 \mathrm{C}=\mathrm{O}$ concentration $\left(1780 \mathrm{~cm}^{-1}\right)$ evolution as a function of oxidation time under different temperatures

The second step corresponds to the period of auto-acceleration of $\mathrm{C}=\mathrm{O}$ formation. This auto-acceleration depends on oxidation temperature and it is more remarkable when the temperature is higher. In the third period, the amount of $\mathrm{C}=\mathrm{O}$ from the formation is almost the same as that of disappearing. As a result, its concentration remains relatively constant. In the case of this study, after 1000 hours of oxidation at $200^{\circ} \mathrm{C}$, the $\mathrm{C}=\mathrm{O}$ concentration tends to be stable.

\section{3 | Evolution of molecular weight}

In order to follow the effect of aging on molecular weight of PPS, the viscosity of virgin and aged samples at molten state has been measured.

In this study, to characterize the thermal aging effects on different properties, five different aging temperatures ranging from $100^{\circ} \mathrm{C}$ to $200^{\circ} \mathrm{C}$ were chosen. It is reasonable to choose $180^{\circ} \mathrm{C}$ than $200^{\circ} \mathrm{C}$ for rheological study. This main reason is that the induction time of oxidation. According to the FTIR results, the induction time at $180^{\circ} \mathrm{C}$ is more than 300 hours while the value at $200^{\circ} \mathrm{C}$ is less than 30 hours. In other words, the aging temperature of $200^{\circ} \mathrm{C}$ leads to more rapid and serious degradation than $180^{\circ} \mathrm{C}$. However, for the purpose of this research, the main goal is to see how the degradation happens at the beginning of oxidation. As a result, it is more logical to see the aging temperature with relatively longer and remarkable induction time since it is more reasonable to characterize the evolution of starting oxidation process rather than the period of serious oxidation at $200^{\circ} \mathrm{C}$.

Table 2 gives the evolution of viscosity obtained from samples with different aging conditions. One can note that the viscosity has some increasing trend from 9700 to $9750 \mathrm{~Pa} \mathrm{~s}^{-1}$ at the beginning of oxidation from 0 to 30 hours. After that, the viscosity decreases with the oxidation time increasing, which means that thermo-oxidation favors to the diminution of molecular chain length during the aging time from 30 to 606 hours at $180^{\circ} \mathrm{C}$. Also, one can see that the thickness of oxidation layer increases from 0 to $113 \mu \mathrm{m}$ during this oxidation period.
TABLE 2 Values of complex viscosity $\eta$ (pa s) as a function of time at the shear rate of $1 \mathrm{~s}^{-1}$ as well as the other parameters (viscosity measurement thickness of plate, $D(\mathrm{~mm})=1$, in the atmosphere of nitrogen at $290^{\circ} \mathrm{C}$ )

\begin{tabular}{lll} 
Time $(\mathrm{h})$ & $\eta($ pa s) & $\begin{array}{l}\text { Thickness of oxidation } \\
\text { layer, } d(\mu \mathrm{m})\end{array}$ \\
\hline Virgin & 9700 & 0 \\
\hline $180^{\circ} \mathrm{C}-30 \mathrm{~h}$ & 9750 & $37 \pm 8.4$ \\
$180^{\circ} \mathrm{C}-48 \mathrm{~h}$ & 3650 & $43 \pm 6.2$ \\
$180^{\circ} \mathrm{C}-240 \mathrm{~h}$ & 3050 & $66 \pm 2.3$ \\
\hline $180^{\circ} \mathrm{C}-571 \mathrm{~h}$ & 3000 & $100 \pm 3.8$ \\
\hline $180^{\circ} \mathrm{C}-606 \mathrm{~h}$ & 1800 & $113 \pm 12.9$ \\
\hline
\end{tabular}

\section{4 | DISCUSSION}

\subsection{Non-Arrhenius nature of induction time}

As discussed, induction time $\left(\tau_{\text {ind }}\right)$ of oxidation phenomenon depends strongly on oxidation temperature. The induction time significantly decreases by increasing the temperature. Table 3 shows the induction time of oxidation at different temperatures. In order to study the nature of this phenomenon, $\ln \tau_{\text {ind }}$ is plotted versus $1 / \mathrm{T}$.

The result of the relationship of $\ln \left(\tau_{\text {ind }}\right)$ versus $1 / T$ is shown in Figure 7. One can see clearly that the curve in this figure is not a linear curve; this may indicate that the Arrhenius Law cannot explain the temperature dependence of the oxidation induction period of PPS/GF.

TABLE 3 Induction time versus oxidation temperature

\begin{tabular}{ll}
\hline $\mathbf{T}\left({ }^{\circ} \mathrm{C}\right)$ & Induction time (h) \\
\hline 140 & 1200 \\
\hline 160 & 890 \\
180 & 260 \\
\hline 200 & 25 \\
\hline
\end{tabular}

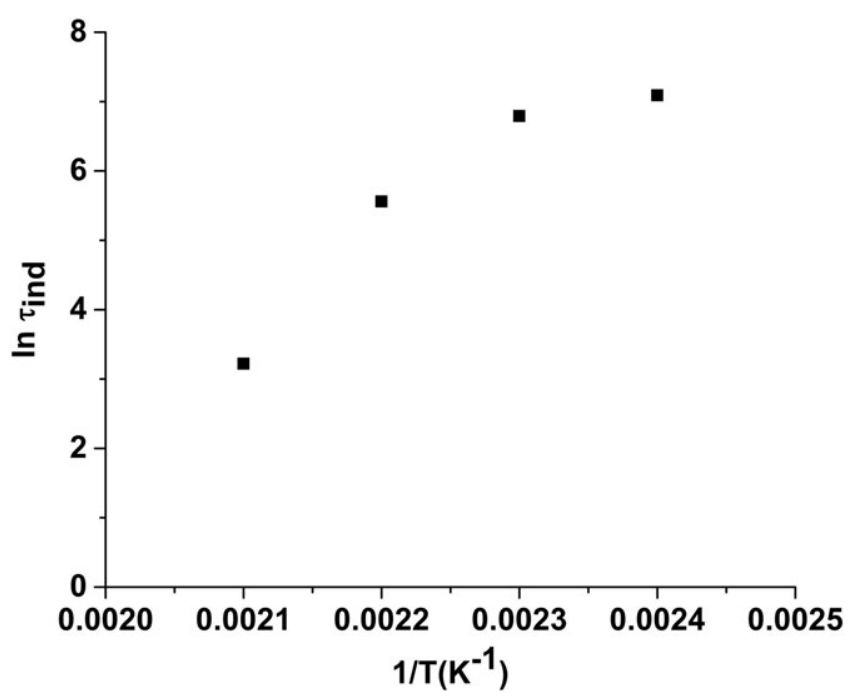

FIGURE 7 The relationship of $\ln \left(\tau_{\text {ind }}\right)$ versus $1 / T$ 
In order to explain intensively and extensively, several tests have been performed.

\section{2 | Rheological properties at molten state during oxidation}

The viscosity at molten state gives information about molecular weight of polymers via the Mark-Houwink equation $\left([\eta]=\eta_{0} \times M^{a}\right)$. That means higher viscosity corresponds to bigger macromolecules. ${ }^{22,23}$

Viscosity measurement was carried out on the sample of PPS/GF in the atmosphere of nitrogen with an isothermal condition of $290^{\circ} \mathrm{C}$. The results are shown in Figure 8 . The viscosity increases obviously with the time increasing. This improvement of viscosity is mainly because of the evolution of molecular weight by postpolycondensation. It should be emphasized that the molecular chain tends to be extended, not shortened with this high temperature.

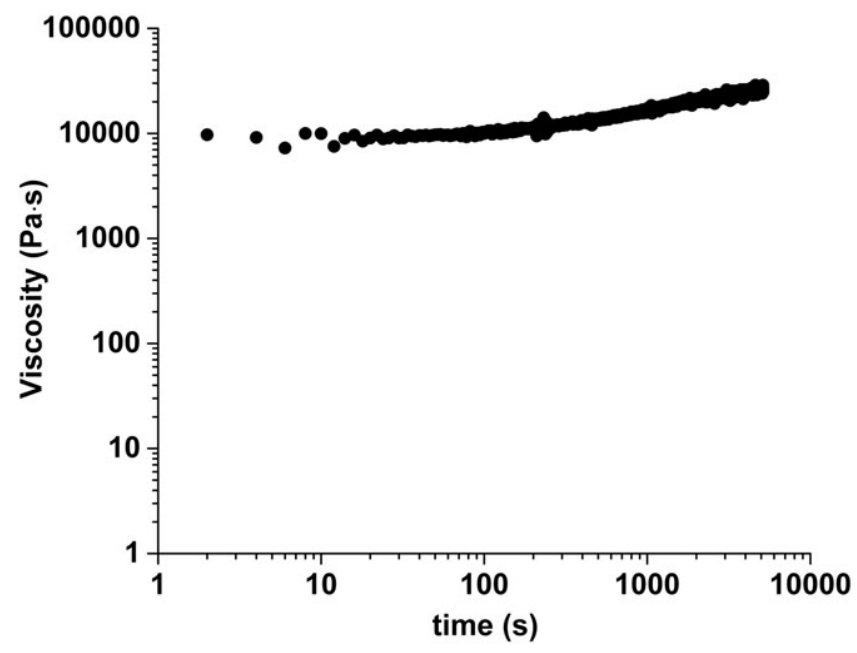

FIGURE 8 Viscosity evolution as a function of time for glass fiberreinforced polyphenylene sulfide (PPS/GF) composite, in the atmosphere of nitrogen at $290^{\circ} \mathrm{C}$
Other rheological tests were performed on virgin and aged (at $180^{\circ} \mathrm{C}$ and $200^{\circ} \mathrm{C}$ ) samples of PPS/GF in the atmosphere of nitrogen at $300^{\circ} \mathrm{C}$. Table 4 and 5 exhibits the evolution of storage modulus and viscosity of PPS/GF aged at different temperatures and times as a function of shear rate. In general, one can note evidently after oxidation, the rheology behavior of PPS/GF at molten state changes significantly.

i. Firstly, for all samples, storage modulus ( $\left.G^{\prime}\right)$ favors to an increasing trend while viscosity $(\eta)$ has a decreasing trend with the shear rate increasing.

ii. Moreover, $\eta$ and $G^{\prime}$ firstly increase and subsequently decrease for aged samples. This process can be accelerated by aging temperature. In detail, for the samples aged at $180^{\circ} \mathrm{C}$ during 100 hours and 390 hours, $\eta$ and $G^{\prime}$ increase, when compared with the virgin sample. This increase of viscosity and storage modulus can be attributed to the cross-linking phenomenon.

iii. Also it is interesting to notice when the oxidation time increases to 503 hours, $\eta$ and $G^{\prime}$ are lower when compared with the aged sample after 390 hours at $180^{\circ} \mathrm{C}$. The decrease of $\eta$ and $G^{\prime}$ after a certain time of aging is attributed to the decrease of molecular weight arising from chains' scission.

iv. Also, in the case of $200^{\circ} \mathrm{C}$, one can see also an obvious increase for the storage modulus and viscosity decrease with the increasing of shear rate.

v. In aspect of thermo-oxidation, the viscosity becomes higher after 100 hours of oxidation. This is also because of the crosslinking in PPS materials. However, after 339 hours of oxidation, the viscosity is very low, even lower than the case of virgin sample because of important chains' scission and obvious drop of molecular weight.

vi. The results also suggest that cross-linking takes place essentially during the induction period of PPS/GF thermo-oxidation. However, this phenomenon may continue even after this period when oxidation reaches to its auto-accelerated step.

TABLE 4 Values of storage modulus ( $\left.G^{\prime}\right)$ of different samples at different shear rates

\begin{tabular}{|c|c|c|c|c|c|c|c|c|c|c|c|}
\hline & \multirow{2}{*}{ PPS/GF } & \multicolumn{10}{|c|}{ Shear rate $\left(\mathrm{s}^{-1}\right)$} \\
\hline & & 0.1 & 0.25 & 0.4 & 1 & 2.5 & 4 & 10 & 25 & 40 & 100 \\
\hline \multirow[t]{4}{*}{$\mathrm{G}^{\prime}(\mathrm{pa})$} & Virgin & 898 & 1430 & 1680 & 2280 & 3050 & 3540 & 4940 & 7290 & 9040 & 14400 \\
\hline & $180^{\circ} \mathrm{C}-503 \mathrm{~h}$ & 2710 & 4930 & 5650 & 7010 & 8640 & 9740 & 12700 & 17300 & 20500 & 29300 \\
\hline & $200^{\circ} \mathrm{C}-100 \mathrm{~h}$ & 4460 & 6400 & 7170 & 8640 & 10400 & 11600 & 14800 & 20100 & 23900 & 36200 \\
\hline & $200^{\circ} \mathrm{C}-339 \mathrm{~h}$ & 132 & 105 & 107 & 119 & 137 & 148 & 163 & 155 & 159 & - \\
\hline
\end{tabular}

TABLE 5 Values of viscosity of different samples at different shear rates

\begin{tabular}{|c|c|c|c|c|c|c|c|c|c|c|c|}
\hline & \multirow{2}{*}{ PPS/GF } & \multicolumn{10}{|c|}{ Shear rate $\left(\mathrm{s}^{-1}\right)$} \\
\hline & & 0.1 & 0.25 & 0.4 & 1 & 2.5 & 4 & 10 & 25 & 40 & 100 \\
\hline \multirow[t]{5}{*}{$\eta($ pa s) } & Virgin & 12800 & 7810 & 5800 & 3170 & 1750 & 1320 & 791 & 505 & 410 & 276 \\
\hline & $180^{\circ} \mathrm{C}-100 \mathrm{~h}$ & 33700 & 17200 & 11900 & 5610 & 2750 & 1970 & 1060 & 610 & 473 & 292 \\
\hline & $180^{\circ} \mathrm{C}-503 \mathrm{~h}$ & 34900 & 22900 & 16300 & 8090 & 4090 & 2950 & 1600 & 899 & 683 & 399 \\
\hline & $200^{\circ} \mathrm{C}-100 \mathrm{~h}$ & 52300 & 28600 & 20100 & 9810 & 4920 & 3550 & 1950 & 1150 & 899 & 570 \\
\hline & $200^{\circ} \mathrm{C}-339 \mathrm{~h}$ & 2670 & 883 & 575 & 257 & 114 & 76.1 & 34.8 & 16 & 10.6 & 4.17 \\
\hline
\end{tabular}


vii. Also, it is worth noting that during the oxidation process of PPS/GF, the cross-linking and chain scissions exist together. At the beginning of oxidation (essentially in induction period), cross-linking is the predominant phenomenon, while the serious chain scissions are more pronounced with the oxidation developing further.

\subsection{Glass transition temperature evolution and mechanical properties}

\subsection{1 | Evolution of glass transition temperature}

Figure 9 shows the $\mathrm{T}_{\mathrm{g}}$ evolution as a function of aging time under different temperatures from $100^{\circ} \mathrm{C}$ to $200^{\circ} \mathrm{C}$. The value of $T_{g}$ is derived from the peak position of loss modulus via the DMA technique at $1 \mathrm{~Hz}$. At all temperatures, with the increase of thermo-oxidation time, $\mathrm{T}_{\mathrm{g}}$ tends to increase because of cross-linking of the PPS. ${ }^{24}$ While with the temperature increasing, the $T_{g}$ also has an improvement. This mainly means that for PPS/GF composites, the $T_{g}$ value is sensitive to the aging time and temperature, ${ }^{24,25}$ and thermal aging leads to the embrittlement phenomenon of PPS/GF composite.

\subsection{2 | Evolution of maximum stress and Young's modulus}

The mechanical properties as a function of aging time under different temperatures are recorded in Figure 10. Firstly, for all temperatures, $\sigma_{\max }$ increases very slightly at the beginning of oxidation because of the cross-linking phenomenon. After then, it drops progressively with the oxidation time increasing. For example, after approximately 3000 hours at $200^{\circ} \mathrm{C}$, the $\sigma_{\max }$ reduces sharply from 84 to $40 \mathrm{MPa}$, while these values at $180^{\circ} \mathrm{C}$ and $100^{\circ} \mathrm{C}$ are 54 and $88 \mathrm{MPa}$, respectively. Also, it should be emphasized that intensive distributions of tensile test values sufficiently reflect the serious mechanical degradation evolution as a function of long time aging. This is also consistent with the DMTA analysis results. According to the DMTA results, one

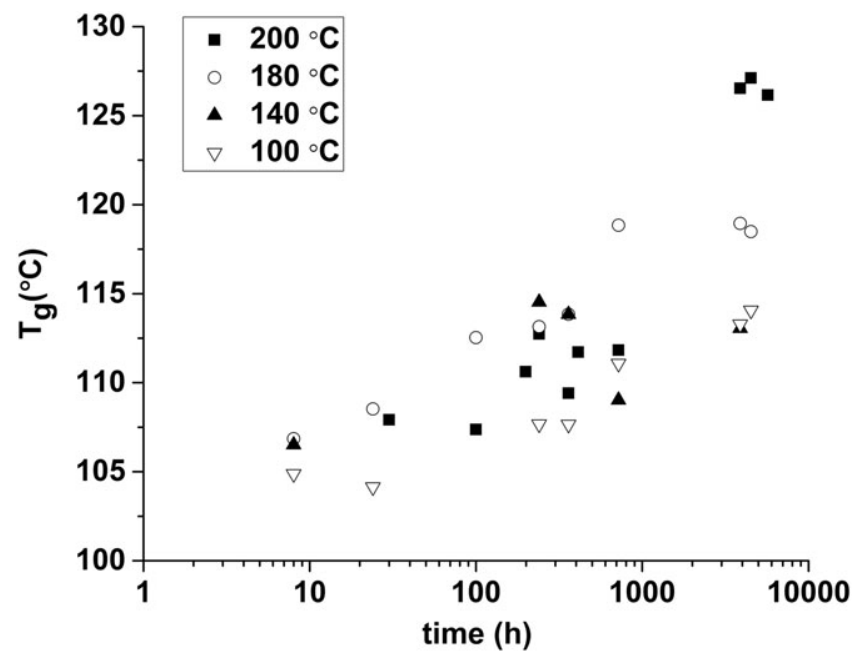

FIGURE $9 \mathrm{~T}_{\mathrm{g}}$ evolution as a function of aging time under different temperatures, obtained from the DMA results at $1 \mathrm{~Hz}$
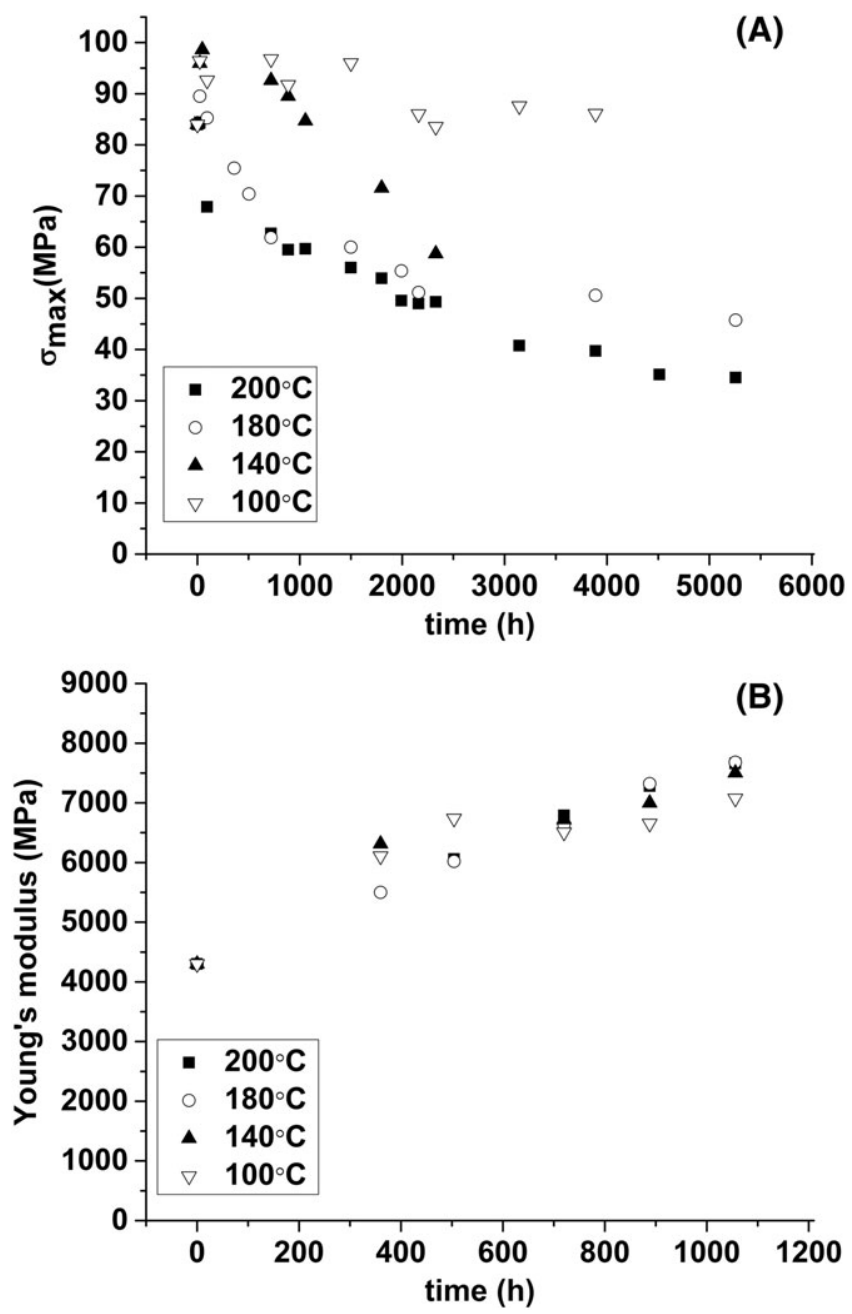

FIGURE 10 (a) Evolution of $\sigma_{\max }$ for glass fiber-reinforced polyphenylene sulfide (PPS/GF), as a function of oxidation time at different temperatures $\left(100^{\circ} \mathrm{C}, 140^{\circ} \mathrm{C}, 180^{\circ} \mathrm{C}\right.$, and $\left.200^{\circ} \mathrm{C}\right)$, and (b) evolution of $\mathrm{E}$ for PPS/GF, as a function of oxidation time at different temperatures $\left(100^{\circ} \mathrm{C}, 140^{\circ} \mathrm{C}, 180^{\circ} \mathrm{C}\right.$, and $\left.200^{\circ} \mathrm{C}\right)$

can note the thermal aging temperature and time can affect sensitively $\mathrm{T}_{\mathrm{g}}$, and $\mathrm{T}_{\mathrm{g}}$ increases dramatically with the higher aging temperature and longer aging time. This indicates thermal aging process triggers the molecular interaction or reaction and limits the mobility of molecules, making the material become brittle, which finally undermines the mechanical properties. ${ }^{26}$

Concerning Young's Modulus, as it can be seen, the virgin sample has a value of $4300 \mathrm{MPa}$. After aging, all of Yong's modulus values increase and this trend becomes more obvious with the aging temperature enhancing. Some researchers also reported that the thermal aging could enhance the Young's modulus. ${ }^{26}$ This is in some extent because of the cross-linking reactions, which restrict the molecular mobility, ${ }^{27}$ and this phenomenon is favored to higher Young's modulus.

\section{4 | Thermo-oxidation mechanism}

\subsection{1 | UV measurement}

In the absence of the supplier's information regarding antioxidant in the PPS/GF under study, UV spectrometry analysis is shown in 
Figure 11 to detect the existing possibility of antioxidants in PPS material. One can see in the range of given spectrum, there is no obvious peak $(283 \mathrm{~nm}$ ) corresponding to the antioxidants (eg, benzophenolic group, $\mathrm{Ar}-\mathrm{OH}){ }^{28,29}$ This may indicate it is not easy to detect the antioxidants. In other words, this may imply that it is not necessary to take the effect of antioxidants into account under this research.

\subsection{2 | Thermo-oxidation mechanism and corre- sponding kinetic equations}

The standard thermo-oxidation mechanism of polymers under air or oxygen condition, which considers simultaneous process, is reported in several research works ${ }^{30-32}$ :

On the basis of this standard mechanism, several researchers explained the degradation mechanism of PPS polymer or PPS composites. ${ }^{9,20,33-36}$

In order to propose an acceptable oxidation mechanism of PPS/GF, the first question is about the energy of different bonds. According to the literature, ${ }^{19,20} \mathrm{C}-\mathrm{S}\left(276 \mathrm{~kJ} \mathrm{~mol}^{-1}\right)$ and $\mathrm{C}-\mathrm{H}$ $\left(414 \mathrm{~kJ} \mathrm{~mol}^{-1}\right)$ bond are weaker than the $\mathrm{C}=\mathrm{C}\left(477 \mathrm{~kJ} \mathrm{~mol}^{-1}\right)$ from the view of bond energy theory. So, the first main scission happens in the position of $\mathrm{C}-\mathrm{S}$ bond or $\mathrm{C}-\mathrm{H}$ bond. In this case, the possible detailed reactions can be shown as follows ${ }^{37}$ :

According to this schema, one can note clearly that the oxidative degradation process contains main routes which can start from the bond position of $\mathrm{C}-\mathrm{S}$ or $\mathrm{C}-\mathrm{H}$. It is noteworthy that, as the past research, ${ }^{30,38}$ the classic oxidative degradation mechanism of PPS can be displayed by the differential equations. With the use of these differential equations, it is possible to calculate quantitatively the $\mathrm{C}=\mathrm{O}$ evolution as a function of time under different oxidative aging temperatures and the detailed equations are as follows:

$$
\begin{aligned}
\frac{\mathrm{d}\left[\mathrm{P}^{\circ}\right]}{\mathrm{dt}}= & 2^{*} k_{1 u}{ }^{*}[\mathrm{POOH}]+k_{1 b}{ }^{*}[\mathrm{POOH}]^{2}-k_{2}{ }^{*}\left[\mathrm{P}^{\circ}\right] *[\mathrm{O}] \\
& +k_{3}{ }^{*}[\mathrm{POO}]^{\circ}{ }^{*}[\mathrm{PH}]-2^{*} k_{4}{ }^{*}\left[\mathrm{P}^{\circ}\right]^{2}-k_{5}{ }^{*}\left[\mathrm{P}^{\circ}\right] *\left[\mathrm{POO}^{\circ}\right] \\
& +k_{h 1}{ }^{*}[\mathrm{PH}],
\end{aligned}
$$

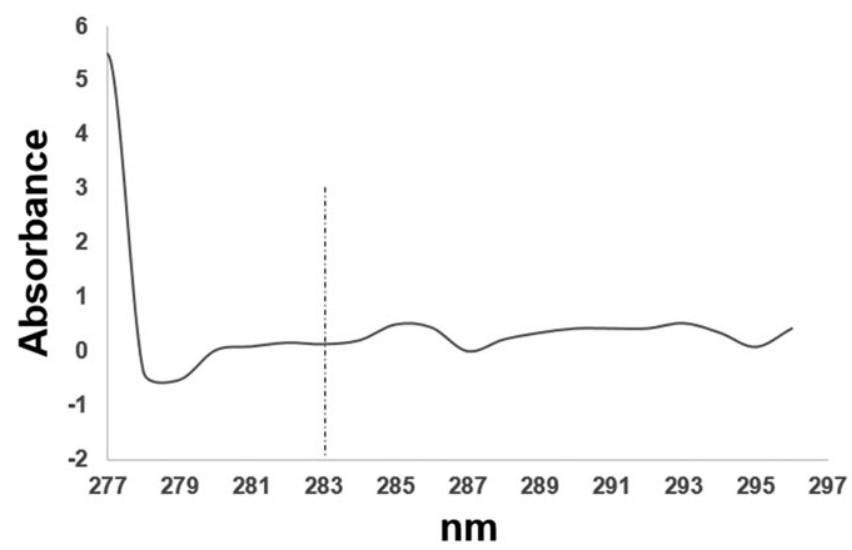

FIGURE 11 Ultraviolet (UV) spectrum of glass fiber-reinforced polyphenylene sulfide (PPS/GF) composites

$$
\begin{aligned}
\frac{\mathrm{d}\left[\mathrm{POO}^{\circ}\right]}{\mathrm{dt}}= & k_{1 b^{*}}{ }[\mathrm{POOH}]^{2}+k_{2}{ }^{*}\left[\mathrm{P}^{\circ}\right] *[\mathrm{O}]-k_{3} *[\mathrm{POO}]^{2} *[\mathrm{PH}] \\
& -k_{5} *\left[\mathrm{P}^{\circ}\right] *\left[\mathrm{POO}^{\circ}\right]-2^{*} k_{6} *\left[\mathrm{POO}^{\circ}\right]^{2},
\end{aligned}
$$

$\frac{\mathrm{d}[\mathrm{POOH}]}{\mathrm{dt}}=-k_{1 u}{ }^{*}[\mathrm{POOH}]-2^{*} k_{1 b}{ }^{*}[\mathrm{POOH}]^{2}+k_{3}{ }^{*}\left[\mathrm{POO}{ }^{\circ}\right] *[\mathrm{PH}]$,

$\frac{\mathrm{d}[\mathrm{PH}]}{\mathrm{dt}}=-k_{3} *[\mathrm{POO}]^{\circ} *[\mathrm{PH}]-k_{\mathrm{s} 1} *[\mathrm{PH}]$

$\frac{\mathrm{d}[\mathrm{CO}]}{\mathrm{dt}}=k_{1 u}{ }^{*}[\mathrm{POOH}]+k_{1 b} *[\mathrm{POOH}]^{2}$

$\frac{\mathrm{d}\left[\mathrm{P}_{1}^{\circ}\right]}{\mathrm{dt}}=k_{\mathrm{s} 1} *[\mathrm{PH}]-k_{\mathrm{s} 2} *\left[\mathrm{P}_{1}^{\circ}\right]\left[\mathrm{P}_{2}^{\circ}\right] *[\mathrm{O}]$,

$\frac{\mathrm{d}\left[\mathrm{P}_{2}^{\circ}\right]}{\mathrm{dt}}=\mathrm{k}_{s 1} *[\mathrm{PH}]-\mathrm{k}_{\mathrm{s} 2} *\left[\mathrm{P}_{1}^{\circ}\right]\left[\mathrm{P}_{2}^{\circ}\right] *[\mathrm{O}]$

Here, $\left[\mathrm{P}^{\circ}\right],\left[\mathrm{POO}^{\circ}\right],[\mathrm{POOH}],[\mathrm{PH}]$ stand for the concentration of alkyls radicals, peroxy radicals, hydroperoxides, and substrate, respectively. Also, two other possible radicals are marked as: $\left[\mathrm{P}_{1}^{0}\right],\left[\mathrm{P}_{2}^{0}\right]$, respectively. The $k$ series represent the kinetic constants of every equation

\section{5 | Modeling results}

It should be emphasized that the concentration of $[\mathrm{C}-\mathrm{S}]$ changes slightly according to the FTIR results. So, it may imply that this Step (1) in Schema 1 is a minor reaction. So, here, some simplification is taken and it is considered that $\left[\mathrm{P}_{1}^{\circ}\right],\left[\mathrm{P}_{2}^{\circ}\right]$ concentrations are very small (approximately 0). Also the classical mechanistic oxidation mechanism (closed loop) mainly takes $k_{1 u}$ to $k_{6}$ into consideration.

On the basis of the analysis in mind, to prove the correctness of our proposed differential equations of oxidative degradation process, the experimental results are verified by the modeling curve from differential equations and we choose the data of $160^{\circ} \mathrm{C}, 180^{\circ} \mathrm{C}$, and $200^{\circ} \mathrm{C}$ as an example.

With the tool of MATLAB software, the simulative verification process can be drawn that it is practical to give a group of random values for $k_{1 u}$ to $k_{6}$ from related literatures and the differential equations are also input into the MATLAB program. Subsequently, these values can be adjusted progressively to obtain a good modeling result. That is to say, this simulative verification process can be converted by solving differential equations and compared with the experimental results (the MATLAB program created by ourselves can realize this process automatically). The modeling results are shown in Figure 12 and in Table 6.

One can see the experimental results are highly superposed with the modeling. This definitely implies that our proposed oxidative degradation mechanism is correct. According to the analysis, one can conclude that with this modeling, we can precise the oxidative degradation process in a quantitative way and predict the lifetime of PPS/GF composites under the service of thermal condition in practice. 


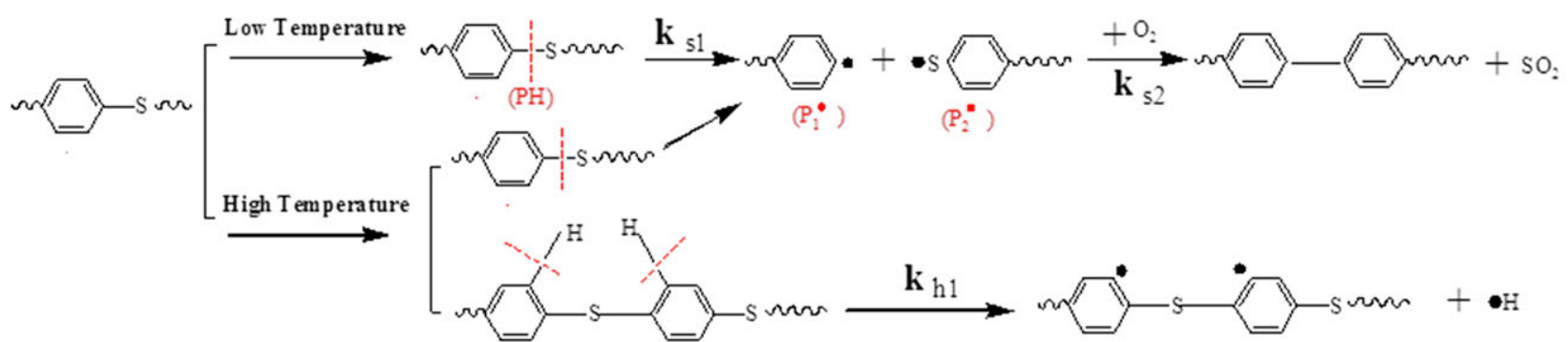

(PH)

(P*)

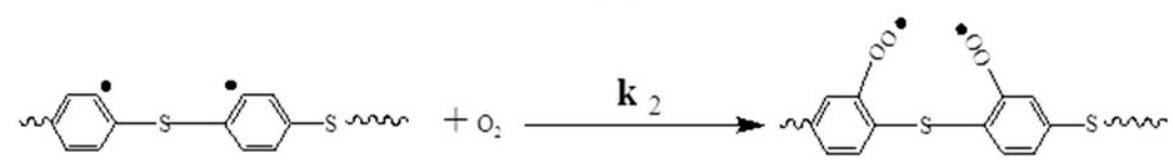

$\left(\mathrm{P}^{*}\right)$

(POO $\left.{ }^{*}\right)$

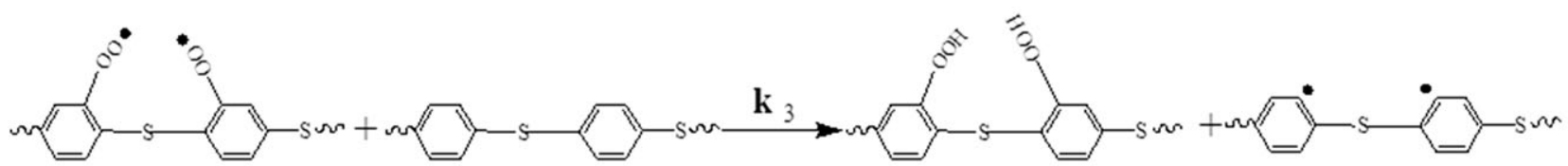

$(\mathrm{POO} \cdot)$

(PH)

(POOH)

(P*)

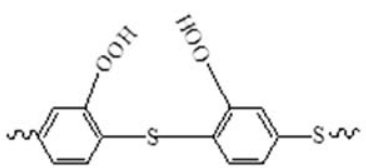

$(\mathrm{POOH})$

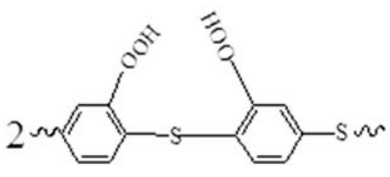

(POOH)

2<smiles>CSc1ccc(SSc2ccc(Cl)cc2)cc1</smiles>

$\left(\mathrm{P}^{\bullet}\right)$

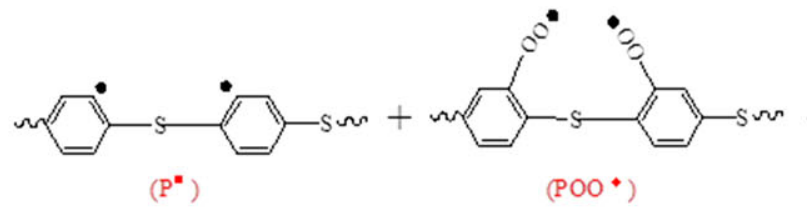

(P")

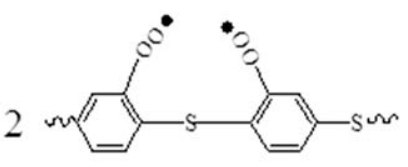

$\left(\mathrm{POO}{ }^{*}\right)$

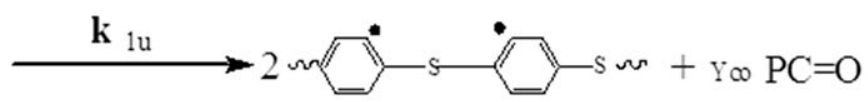

(P")

SCHEMA 1 Possible schematic diagram for the degradation of PPS/GF composite in air. [Colour figure can be viewed at wileyonlinelibrary.com]

With the help of the Arrhenius equation:

$$
\ln k=-\frac{E_{a}}{R T}+\ln A
$$

We can also calculate the corresponding activation energy values according to the rate constants (see Figure 13 and Table 7).

One can have the following comments:
- For $k_{1 u}$, it corresponds to activation energy of $33.4 \mathrm{~kJ} \mathrm{~mol}^{-1}$ and it is highest among all values. This means that the reaction related to $k_{1 u}$ is highly dependent on the aging temperature and increasing temperature can favor higher unimolecular hydroperoxide. In a wide range researches using classic polymer oxidation mechanism, ${ }^{39-41}$ the activation energy is always the maximum. Why is always this case? Because this step (hydroperoxide build-up) is 


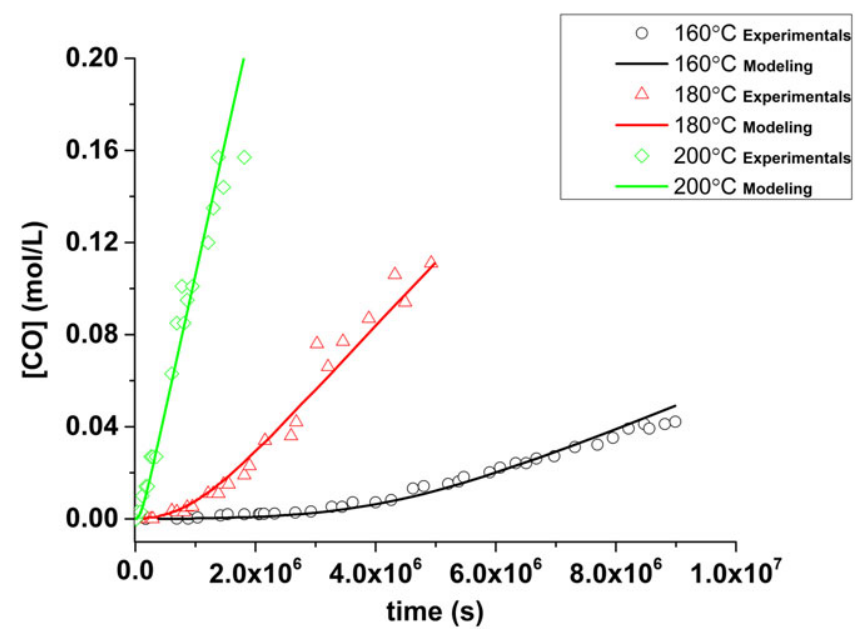

FIGURE 12 Modeling results of the thermo-oxidative equations at the peak of $1780 \mathrm{~cm}^{-1}$ under different aging temperatures: $160^{\circ} \mathrm{C}, 180^{\circ} \mathrm{C}$, and $200^{\circ} \mathrm{C}$ [Colour figure can be viewed at wileyonlinelibrary.com]

the controlling-speeding step for the oxidation, and it decides the fastness or slowness of the oxidation process.

- For $k_{1 b}$, one can note that the corresponding activation energy is $4 \mathrm{~kJ} \mathrm{~mol}^{-1}$, which is obviously lower than the value of $k_{1 u}$. This implies that bimolecular hydroperoxide build-up is less sensitive to the aging temperature when compared with unimolecular hydroperoxide build-up. In addition, one can see that with the aging temperature increasing, $k_{1 u}$ and $k_{1 b}$ are more and more approaching the same values.

- For $k_{2}$, the activation energy is $8.4 \mathrm{~kJ} \mathrm{~mol}^{-1}$ and the constant of $k_{2}$ can be affected by aging temperature. It is interesting to note that " $k_{2}>k_{1}$." This is the step of propagation, which indicates the propagation process is highly quick and will finish once the initiation process starts.

- For $k_{3}$, the activation energy is $11.1 \mathrm{~kJ} \mathrm{~mol}^{-1}$ and it is interesting to note that " $k_{2}>>k_{3}>k_{1}$." This is also the step of propagation. In addition, it should be noted that radical $\mathrm{POO}^{\circ}$ is less stable than radical $\mathrm{P}^{\circ}$. If there is enough oxygen, $\mathrm{POO}^{\circ}$ will react very faster than $\mathrm{P}^{\circ}$

- For $k_{4}, k_{5}$, and $k_{6}$, the activation energies are very small (near $0 \mathrm{~kJ} \mathrm{~mol}^{-1}$ ). This mainly indicates that the termination process is insensitive to the aging temperature.

- Moreover, the constants have the following order: $k_{4}>k_{5}>k_{6}$, $k_{2}>k_{3}>k_{1}$, which are in high agreement with other wide ranges of researches. ${ }^{39-42}$

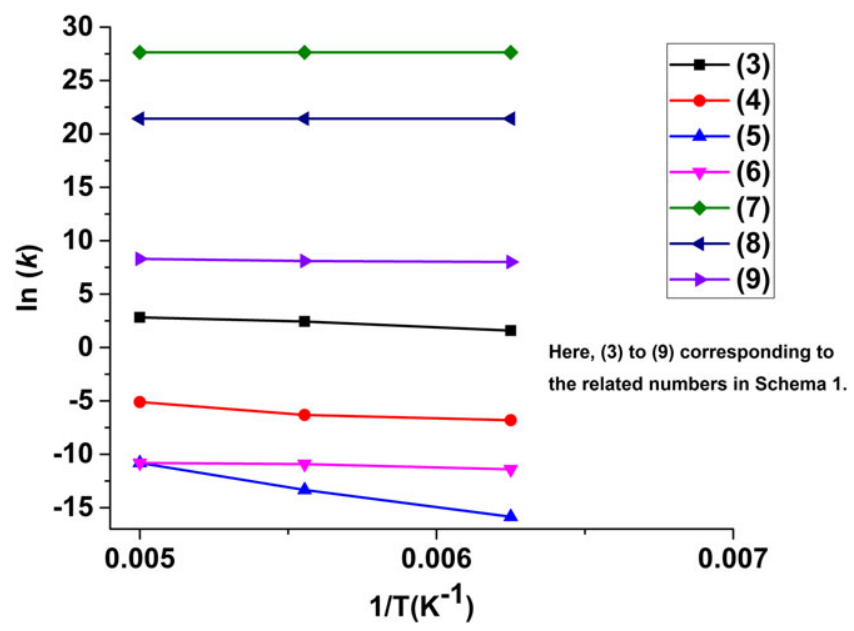

FIGURE 13 Relationship of In (k) versus 1/T [Colour figure can be viewed at wileyonlinelibrary.com]

\section{6 | Influence of thermo-oxidative temperatures}

It is worthy noticing that the slope of the propagation step (see Figure 14 and Table 8) obtained from the concentration [ $\mathrm{C}=\mathrm{O}$ ] curve, is a good parameter to characterize the kinetic process of PPS oxidation.

Moreover, with the combination of the Arrhenius equation, one can calculate the activation energy, which is $20.7 \mathrm{~kJ} \mathrm{~mol}^{-1}$ and the $R^{2}$ is 0.99 (see Figure 15). These two methods give us a good guidance to calculate the thermal oxidation activation energy of PPS/GF composites.

According to the results, one can clearly conclude that the thermo-oxidation of PPS is highly sensitive to the applied temperature. Once the oxidation temperature increases, the induction time will shorten and the lifetime has an inverse trend.

As one can see, Figure 16 shows the comparison of the OM photos before and after degradation. The samples come from the dog-bone-shaped specimen with a crossing section surface before and after degradation. One can see the crossing section surface of virgin sample has a continuous and consistent gray color without any obvious difference while for the sample aged 5256 hours at $200^{\circ} \mathrm{C}$, one can see the edge of crossing section surface has an obvious dark color and the degree of darkness tends to be light from exterior to interior. This change of color can mainly prove that the serious degradation happens in PPS/GF composite. In addition, because of the limitation of oxygen diffusion, the degradation trend of interior parts is less serious than that of exterior parts.

TABLE 6 Rate constants determined by inverse method

$\begin{array}{llllllll} & k_{1 u}\left(\mathrm{~s}^{-1}\right) & k_{1 b}\left(\mathrm{I} \mathrm{Mol}^{-1} \mathrm{~s}^{-1}\right) & k_{2}\left(\mathrm{I} \mathrm{Mol}^{-1} \mathrm{~s}^{-1}\right) & k_{3}\left(\mathrm{I} \mathrm{Mol}^{-1} \mathrm{~s}^{-1}\right) & k_{4}\left(\mathrm{I} \mathrm{Mol}^{-1} \mathrm{~s}^{-1}\right) & k_{5}\left(\mathrm{I} \mathrm{Mol}^{-1} \mathrm{~s}^{-1}\right) & k_{6}\left(\mathrm{Mol}^{-1} \mathrm{~s}^{-1}\right) \\ T=160^{\circ} \mathrm{C} & 1.3 \times 10^{(-7)} & 1.1 \times 10^{(-5)} & 1.3 \times 10^{6} & 1.1 \times 10^{(-3)} & 1.0 \times 10^{12} & 2.0 \times 10^{9} & 3.0 \times 10^{3} \\ T=180^{\circ} \mathrm{C} & 1.6 \times 10^{(-6)} & 1.8 \times 10^{(-5)} & 1.5 \times 10^{6} & 1.8 \times 10^{(-3)} & 1.0 \times 10^{12} & 2.0 \times 10^{9} & 3.4 \times 10^{3} \\ T=200^{\circ} \mathrm{C} & 2.0 \times 10^{(-5)} & 2.0 \times 10^{(-5)} & 1.6 \times 10^{6} & 6.0 \times 10^{(-3)} & 1.0 \times 10^{12} & 2.0 \times 10^{9} & 4.0 \times 10^{3}\end{array}$


TABLE 7 Activation energy determined by inverse method

\begin{tabular}{|llllllll}
\hline Number in Schema 1 & $(3)$ & $(4)$ & $(5)$ & (6) & (7) & (8) & (9) \\
\hline Activation energy $\left(\mathrm{kJ} \mathrm{mol}^{-1}\right)$ & 8.4 & 11.1 & 33.4 & 4.0 & 0 & 1.8 \\
\hline$R^{2}$ & 0.98 & 0.91 & 0.99 & 0.91 & 1 & 1 \\
\hline
\end{tabular}

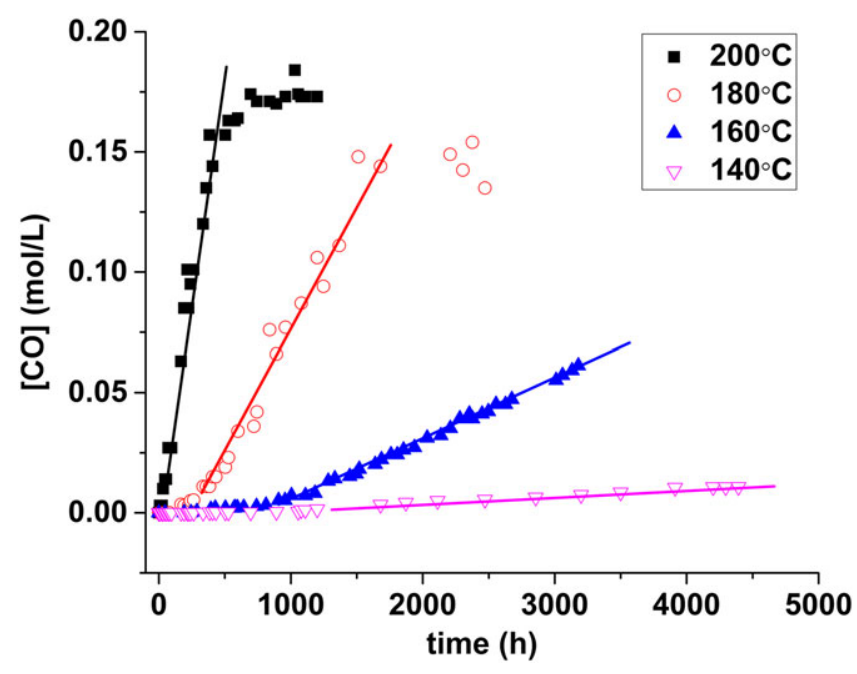

FIGURE 14 The slope of the concentration $[C=O$ ] in different oxidation temperatures, in step of propagation [Colour figure can be viewed at wileyonlinelibrary.com]

TABLE 8 Rate constants determined by inverse method in step of propagation

\begin{tabular}{ll}
$T\left({ }^{\circ} \mathrm{C}\right)$ & Slope \\
140 & $1.8^{*} 10^{\wedge}(-6)$ \\
160 & $2.3^{*} 10^{\wedge}(-5)$ \\
180 & $1.2^{*} 10^{\wedge}(-4)$ \\
200 & $3.6^{*} 10^{\wedge}(-4)$ \\
\hline
\end{tabular}

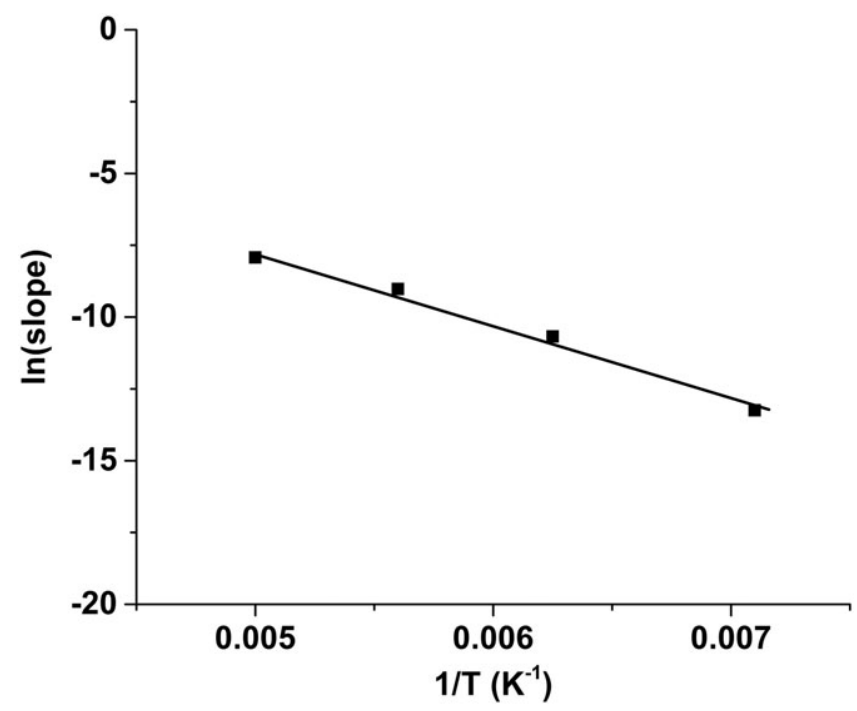

FIGURE 15 The relationship of In (slope) versus 1/T

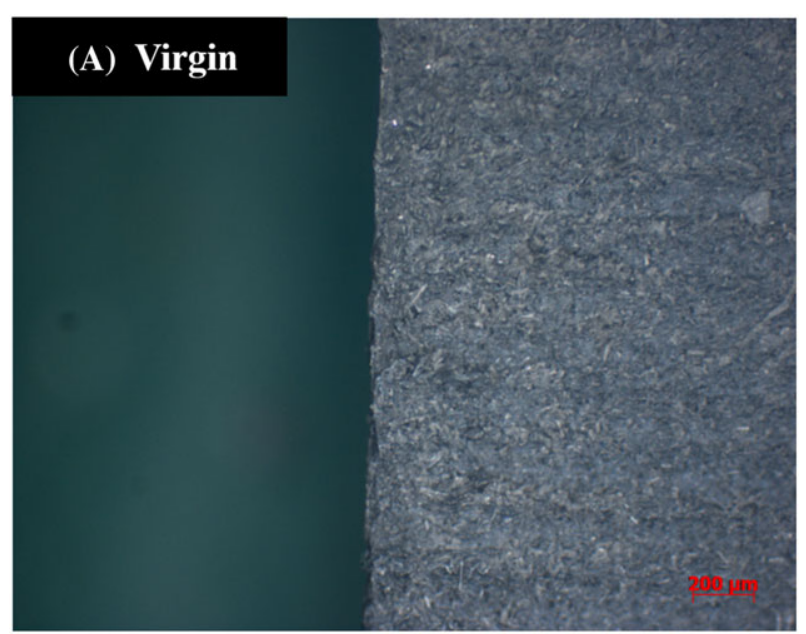

(B) $200{ }^{\circ} \mathrm{C}-5256 \mathrm{~h}$

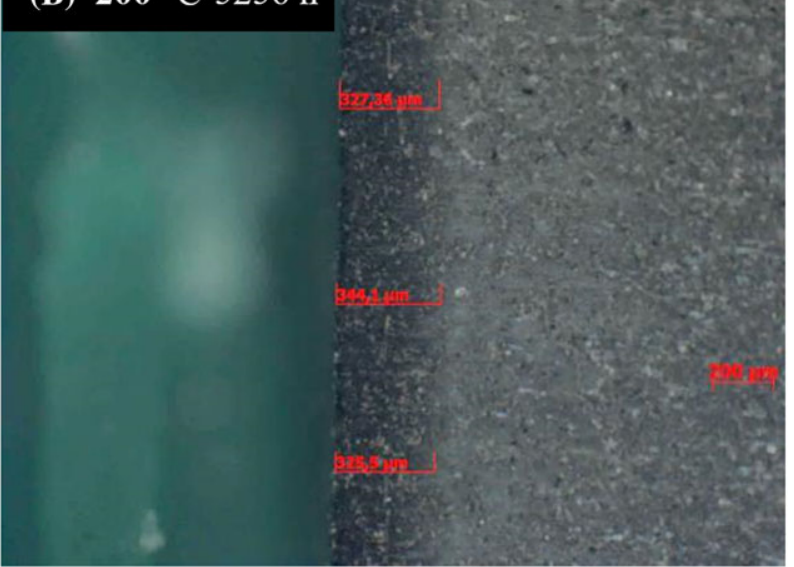

FIGURE 16 (a) Optical microscopy observation on crossing section surface of virgin sample, and (b) optical microscopy observation on crossing section surface of sample aged at $200^{\circ} \mathrm{C}-5256$ hours [Colour figure can be viewed at wileyonlinelibrary.com]

\section{5 | CONCLUSIONS}

In this paper, the mechanism and modeling of thermo-oxidation for PPS/GF composites were studied. The main results are as follows:

According to the rheological results, during the oxidation process of PPS materials, the cross-linking and chain scissions exist together. At the beginning of oxidation, it is easier to see the cross-linking phenomenon, while the chain scissions are more pronounced with the oxidation developing further. In addition, to PPS/GF composites, the $\mathrm{T}_{\mathrm{g}}$ value is sensitive to the aging time and temperature. Also, the mechanical strength first increases and subsequently decreases with the aging time and aging temperature increasing because of the predominance of embrittlement arising from thermal aging. In the end, 
the possible schematic diagram for the degradation of PPS/GF composites was confirmed by the combination of experimental results and modeling of the differential equations from our proposed thermo-oxidative degradation mechanism. In general, higher temperature and longer oxidation time lead this PPS/GF material into more obvious degradation.

\section{ACKNOWLEDGEMENTS}

The authors are grateful to Dr. R.C. Benevides and Dr. Manuel Henner (Valeo) for collaboration and fruitful discussions. Valeo Company is also gratefully acknowledged for providing the material. Financial support from the CASCADE program under project "FSN Calcul Intensif et Simulation Numérique" by DGE is gratefully acknowledged.

The authors also thank China Scholarship Council (CSC) for their funding of Peiyuan Zuo's thesis.

\section{ORCID}

Peiyuan Zuo (D) http://orcid.org/0000-0003-3140-8650

\section{REFERENCES}

1. Hill HW, Brady D. Properties, environmental stability, and molding characteristics of polyphenylene sulfide. Polym Eng Sci. 1976;16(12):831-835.

2. López LC, Wilkes GL. Non-isothermal crystallization kinetics of poly (pphenylene sulphide). Polymer. 1989;30(5):882-887.

3. Caramaro L, Chabert B, Chauchard J, Vu-Khanh T. Morphology and mechanical performance of polyphenylenesulfide carbon fiber composite. Polym Eng Sci. 1991;31(17):1279-1285.

4. Favaloro M. Properties and processes of linear polyphenylene sulfide (PPS) for continuous fiber composites aerospace applications. SAE International2009.

5. Zuo P, Benevides RC, Laribi MA, et al. Multi-scale analysis of the effect of loading conditions on monotonic and fatigue behavior of a glass fiber reinforced polyphenylene sulfide (PPS) composite. Composites Part B. 2018;145:173-181.

6. Ma Y, Cong P, Liu X, Lv R, Li T. Effect of heat treatment on the mechanical and tribological properties of polyphenylene sulfide fiber materials. J Macromol Sci, Part B. 2014;53(12):1786-1799.

7. Zhai H, Zhou X, Fang L, Lu A. Study on mechanical properties of powder impregnated glass fiber reinforced poly (phenylene sulphide) by injection molding at various temperatures. J Appl Polym Sci. 2010;115(4):2019-2027.

8. Pantelakis SG, Katsiropoulos CV, Lefebure P. Effect of thermal treatment on the tensile and in-plane shear behavior of carbon fiberreinforced poly (phenylene sulfide) composite specimens. J Appl Polym Sci. 2008;107(5):3190-3199.

9. Yamashita T, Tomitaka H, Kudo T, Horie K, Mita I. Degradation of sulfur-containing aromatic polymers: Photodegradation of polyethersulfone and polysulfone. Polym Degrad Stab. 1993;39(1):47-54.

10. Ehlers G, Fisch K, Powell W. Thermal degradation of polymers with phenylene units in the chain. II. Sulfur-containing polyarylenes. J Polym Sci, Part A: Polym Chem. 1969;7:2955-2967.

11. Li XG, Huang MR, Bai H, Yang YL. High-resolution thermogravimetry of polyphenylene sulfide film under four atmospheres. J Appl Polym Sci. 2002;83(10):2053-2059.

12. Black R, List C, Wells R. Thermal stability of $p$-phenylene sulphide polymers. J Appl Chem. 1967;17:269-275.

13. Deslauriers P, Geibel JF, Das P. Aspects of poly ( $p$-phenylene sulfide) degradation and stabilization. Part 1. Influence of polymer end groups on exposure induced coloration. Die Angewandte Makromolekulare Chemie. 1997;247(1):45-59.
14. Perng L. Thermal decomposition characteristics of poly (phenylene sulfide) by stepwise Py-GC/MS and TG/MS techniques. Polym Degrad Stab. 2000;69(3):323-332.

15. Christopher N, Cotter J, Knight G, Wright W. Thermal degradation of poly (phenylene sulfide) and perfluoropoly (phenylene sulfide). J Appl Polym Sci. 1968;12(4):863-870.

16. Lisa G, Hamciuc C, Hamciuc E, Tudorachi N. Thermal and thermooxidative stability and probable degradation mechanism of some polyetherimides. J Anal Appl Pyrolysis. 2016;118:144-154.

17. Jing C, Lei Y, Jieping Z, Sidong L, Yongjun C, Kui X. Drying kinetics and cross-linking of sulfur prevulcanized thick natural rubber latex film. Rubber Chem Technol. 2013;86(1):57-67.

18. Matyshak V, Krylov O. Problems of quantitative spectroscopic measurements in heterogeneous catalysis: molar absorption coefficients of vibrations in adsorbed substances. Kinet Catal. 2002;43(3):391-407.

19. Li XG, Huang MR, Bai H. High-resolution thermogravimetry of poly (phenylene sulfide) film under four atmospheres. J Appl Polym Sci. 2002;83(9):1940-1946.

20. George K, Komalan C, Kumar P, Varughese K, Thomas S. Dynamic mechanical analysis of binary and ternary polymer blends based on nylon copolymer/EPDM rubber and EPM grafted maleic anhydride compatibilizer. 2007.

21. Zuo P, Fitoussi J, Shirinbayan M, Bakir F, Tcharkhtchi A. Thermal aging effects on overall mechanical behavior of short glass fiber reinforced polyphenylene sulfide composites. Polym Eng Sci. 2018. In press

22. Stacy CJ. Molecular weight distribution of polyphenylene sulfide by high temperature gel permeation chromatography. J Appl Polym Sci. 1986;32(3):3959-3969.

23. Housaki T, Satoh K. Molecular weight distribution of polyphenylene sulfide by high temperature gel permeation chromatography. Polym J. 1988;20(12):1163-1166.

24. Bandyopadhyay A, Valavala PK, Clancy TC, Wise KE, Odegard GM. Molecular modeling of crosslinked epoxy polymers: the effect of crosslink density on thermomechanical properties. Polymer. 2011;52(11):2445-2452.

25. Yang J, Xu T, Lu A, Zhang Q, Tan H, Fu Q. Preparation and properties of poly ( $p$-phenylene sulfide)/multiwall carbon nanotube composites obtained by melt compounding. Compos Sci Technol. 2009;69(2):147-153.

26. Shafee EE. Effect of aging on the mechanical properties of coldcrystallized poly (trimethylene terephthalate). Polymer. 2003;44(13):3727-3732.

27. Kim SY, Lee TH, Park YI, et al. Influence of material properties on scratch-healing performance of polyacrylate-graft-polyurethane network that undergo thermally reversible crosslinking. Polymer. 2017;128:135-146.

28. Richaud E. Kinetic modelling of phenols consumption during polyethylene thermal oxidation. Eur Polym J. 2013;49(8):2223-2232.

29. Richaud E. Durabilité des géotextiles en polypropylène: Arts et Métiers ParisTech; 2006.

30. Richaud E, Farcas F, Fayolle B, Audouin L, Verdu J. Hydroperoxide build-up in the thermal oxidation of polypropylene-a kinetic study. Polym Degrad Stab. 2007;92(1):118-124.

31. Rychly J, Matisova-Rychla L, Csmorova K, et al. Kinetics of mass changes in oxidation of polypropylene. Polym Degrad Stab. 1997;58(3):269-274.

32. Tcharkhtchi A, Farzaneh S, Abdallah-Elhirtsi S, Esmaeillou B, Nony F, Baron A. Thermal aging effect on mechanical properties of polyurethane. Int J Polym Anal Charact. 2014;19(7):571-584.

33. Landel RF, Nielsen LE. Mechanical Properties of Polymers and Composites. 2nd Edition. CRC Press; 1993. ISBN 9780824789640.

34. Kim K, Lee C, Kim P, Ryu B. Dielectric properties on the radiation and thermal aged PEEK. Solid Dielectrics, 2004 ICSD 2004 Proceedings of the 2004 IEEE International Conference on: IEEE; 2004. p. 332-335. 
35. Kang PH, Lee C, Kim KY. Radiation and thermal effects on the dielectric relaxation properties of PEEK. J Ind Eng Chem -Seoul-. 2007;13:250.

36. Ibarra L, Macias A, Palma E. Viscoelastic properties of short carbon fiber thermoplastic (SBS) elastomer composites. J Appl Polym Sci. 1995;57(7):831-842.

37. Ernault E, Richaud E, Fayolle B. Thermal-oxidation of epoxy/amine followed by glass transition temperature changes. Polym Degrad Stab. 2017;138:82-90.

38. Tobolsky AV, Metz DJ, Mesrobian RB. Low temperature autoxidation of hydrocarbons: the phenomenon of maximum Rates1, 2. J Am Chem Soc. 1950;72(5):1942-1952.

39. Richaud E, Fayolle B, Verdu J. Polypropylene stabilization by hindered phenols-kinetic aspects. Polym Degrad Stab. 2011;96(1):1-11.

40. Richaud E, Monchy-Leroy C, Colin X, Audouin L, Verdu J. Kinetic modelling of stabilization coupled with stabilizer loss by evaporation.
Case of dithioester stabilized polyethylene. Polym Degrad Stab. 2009;94(11):2004-2014.

41. El-Mazry C, Hassine MB, Correc O, Colin X. Thermal oxidation kinetics of additive free polyamide 6-6. Polym Degrad Stab. 2013;98(1):22-36.

42. Mikdam A, Colin X, Minard G, Billon N, Maurin R. A kinetic model for predicting the oxidative degradation of additive free polyethylene in bleach desinfected water. Polym Degrad Stab. 2017;146:78-94.

How to cite this article: Zuo P, Tcharkhtchi A, Shirinbayan M, Fitoussi J, Bakir F. Multiscale physicochemical characterization of a short glass fiber-reinforced polyphenylene sulfide composite under aging and its thermo-oxidative mechanism. Polym Adv Technol. 2019;30:584-597. https://doi.org/10.1002/pat.4495 